\title{
PLATUS KRAUJUOJANTIS SKRANDŽIO PAŽEIDIMAS, PAVARTOJUS NESTEROIDINIŲ VAISTŲ NUO UŽDEGIMO. KLINIKINIS ATVEJIS
}

\author{
Paulina Tekoriutė ${ }^{1}$, Monika Matuliauskaitė ${ }^{1}$, Aistė Šakalytė ${ }^{1}$, Laimas Virginijus Jonaitis ${ }^{2}$ \\ ${ }^{1}$ Lietuvos sveikatos mokslu universiteto Medicinos fakultetas, \\ ${ }^{2}$ Lietuvos sveikatos mokslu universiteto Medicinos akademijos Gastroenterologijos klinika
}

Raktažodžiai: skrandžio vėžys, opa, nesteroidiniai vaistai nuo uždegimo.

\begin{abstract}
Santrauka
Nesteroidiniai vaistai nuo uždegimo (NVNU) yra pagrindinè vaistų grupé, pasižyminti analgetiniu, antipiretiniu bei priešuždegiminiu poveikiu. Nepaisant plataus naudojimo ligų gydymui, NVNU gali sukelti ịvairų šalutini poveikị: neretai paveikiamas virškinamasis traktas. Skrandžio bei dvylikapirštès žarnos peptinès opos (PO) yra dažniausia komplikacija, kuri išsivysto dèl šių vaistų vietinio bei sisteminio poveikio. Kraujavimas iš opos yra dažniausia opaligès komplikacija, pasireiškianti 15-20 proc. pacientų. Straipsnyje pristatomas 63 metų vyro, gydyto dèl ūminio kraujavimo iš skrandžio opos, kurị sukèlè trumpalaikis intensyvus gydymas NVNU, klinikinis atvejis. Praejus 12 dienų nuo NVNU vartojimo pradžios, pacientui pasireiškè ūmus vẻmimas kraujo krešuliais. Atlikus fibroezofagogastroduodenoskopiją (FEGDS), rastas platus, apie 1/3 cirkuliaraus skrandžio spindžio apimantis išopejjimas mažojoje kreivèje ir užpakalinèje sienelèje. Itartas navikinis skrandžio pažeidimas. Diferencinei diagnostikai paimta biopsija iš opos kraštu. Taikytas medikamentinis gydymas, gautas teigiamas klinikinis efektas. Pacientas išleistas tolesniam ambulatoriniam gastroenterologo stebejjimui ir gydymui.
\end{abstract}

\section{İvadas}

Opaligès komplikacijos yra didelè sveikatos priežiūros sistemos problema. Jas gali lemti tiek padidèjęs NVNU vartojimas, tiek didẻjantis pagyvenusių žmonių skaičius daugelyje šalių [2]. Higienos instituto duomenimis, 2019 metais suaugusiujų, sergančių skrandžio, dvylikapirštės žarnos ar gastrojejuninėmis opomis, skaičius Lietuvoje siekè 16298, sergamumas $-7,10$ atvejo 1000 gyventojų [1]. Skrandžio ar dvylikapirštes žarnos peptinès opos, atsiradusios dèl $\mathrm{He}$ licobacter pylori infekcijos ar NVNU vartojimo, yra daž- niausia kraujavimo iš viršutinès virškinamojo trakto (VT) dalies priežastis [3]. NVNU 5-6 kartus padidina kraujavimo iš virškinamojo trakto riziką, kiekvieno kraujavimo epizodo mirtingumas siekia maždaug 12 procentu [4].

Darbo tikslas - pristatyti trumpalaikio NVNU vartojimo sukelto plataus skrandžio pažeidimo klinikini atveji rūkančio, gausiai vartojančio kofeiną paciento, infekuoto Helicobacter pylori.

\section{Klinikinis atvejis}

63 metų vyras stacionarizuotas ị rajono ligoninę dèl gausaus vėmimo kraujo krešuliais. Pacientas skundèsi pykinimu, silpnumu, apetito stoka, kūno svorio kritimu, skausmu po kairiuoju šonkaulių lanku. Iš anamnezès buvo žinoma, jog susirgo prieš 3 savaites, kai atsirado skausmas širdies plote - ịtarta kardiologine patologija, tačiau, atlikus tyrimus, atmesta. Diagnozuota tarpšonkaulinio nervo neuralgija, skirtas gydymas NVNU. Paciento teigimu, skausmo malšinimui jis vartojo didelị NVNU kiekị - po keletą ịvairių rūšių tablečių nuo skausmo per dieną. Surinkus anamnezę sužinota, jog pacientas rūko apie 45 metus po du pakelius per dieną, vartoja daug kavos - iki 7-8 puodelių per dieną, nereguliariai maitinasi ir patiria daug streso darbe. Praejus 12 dienų nuo vaistų vartojimo pradžios, atsirado staigus pykinimas ir gausus vèmimas kraujo krešuliais. Iškviesta greitoji medicinos pagalba, pacientas pervežtas ị rajono ligoninę.

Atliktuose kraujo tyrimuose stebeta pohemoraginè ane-

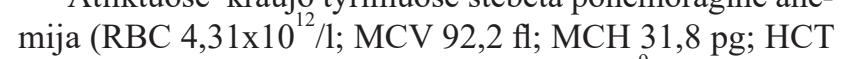
$30,9 \%$; HGB $93 \mathrm{~g} / 1)$, leukocitozè $(12,7 \times 10 / 1)$, padidèjęs C-reaktyvusis baltymas $(171,4 \mathrm{mg} / \mathrm{l})$. Atlikta FEGDS, skrandyje rastas už įskrandžio prasidedantis išopejjimas, apimantis mažają kreivę ir abi sienas, kietu, nelygiu dugnu bei fiksuotu krešuliu paviršiuje. Itartas skrandžio věžys, tačiau biopsijos nebuvo paimtos. Skirtas gydymas sol. Esomeprasoli $80 \mathrm{mg}$ ir sol. $\mathrm{NaCl} 0,9$ proc. $15 \mathrm{ml}$ boliusu ị veną, toliau tęsiant sol. Esomeprasoli $8 \mathrm{mg} / \mathrm{val}$. ir sol. $\mathrm{NaCl} 0,9$ proc. $50 \mathrm{ml}$ automatine švirkštine pompa (AŠP) į veną. Kitą gydymo 
stacionare dieną pacientui pakartota FEGDS, kurios metu stebètas didelis išopejjimas, apimantis apie $1 / 3$ cirkuliaraus spindžio. Nesant aktyvaus kraujavimo požymių, įtartas išopejjęs skrandžio navikas su buvusio kraujavimo požymiais. Pacientui perpilti 2 vnt. šviežiai šaldytos plazmos bei 2 vnt. eritrocitų masès. Trečiają gydymo stacionare dieną pacientui perpilti dar 2 vnt. eritrocitų masès. Pakartotuose kraujo tyrimuose žymesnès neigiamos dinamikos nebuvo, išliko

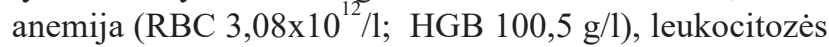
nebuvo, C-reaktyvusis baltymas siekè $60,1 \mathrm{mg} / \mathrm{l}$. Gydymo metu kraujavimas nesikartojo.

Esant neaiškiai kraujavimo priežasčiai ir ịtariant skrandžio naviką, tolimesniam ištyrimui ir gydymui pacientas buvo perkeltas ị Lietuvos sveikatos mokslų universiteto Kauno klinikų gastroenterologijos skyrių. Pakartotuose laboratoriniuose tyrimuose išliko anemija (RBC 2,99 $10 \%$; HGB 96 g/l). Atlikta FEGDS: apatiniame-viduriniame skrandžio trečdaliuose nustatytas platus, apie $1 / 3$ skrandžio apèmęs cirkuliaraus spindžio išopėjimas (labiau apimantis mažają kreivę ir užpakalinę sienelę), kurio dugnas padengtas fibrinu (1 pav.). Paimtos biopsijos iš opos kraštų. Pacientui atlikta krūtinès ir pilvo kompiuterine tomografija: skrandžio mažojoje kreiveje buvo matoma lokaliai iki $1,2 \mathrm{~cm}$ sustorèjusi sienelè, greta jos - du iki $0,9 \mathrm{~cm}$ padidèję limfmazgiai bei šalia kepenų, ties priekine pilvo siena keli iki $0,5 \mathrm{~cm}$ dydžio limfmazgiai. Itartas skrandžio navikas, kuris radiologiškai atitiktų T2N1M0. Gautas histologinio tyrimo atsakymas, patologo formuota išvada: lètinis aktyvus gastritas su žarnine metaplazija ir progresuojančiu išopejjimu. Biopsijoje, paimtoje iš opos kraštu, H.pylori infekcija nenustatyta.

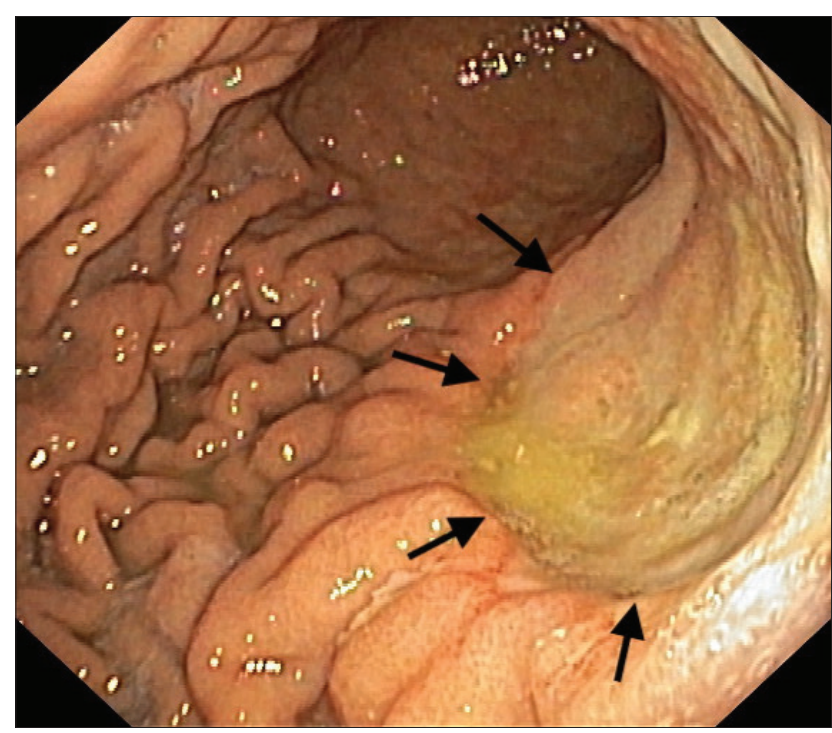

1 pav. Didelè lètinė užpakalinès skrandžio sienelès opa
Pakartota FEGDS: išlikęs platus, 1/3 skrandžio cirkuliaraus spindžio apėmęs išopejjimas apatiniame-viduriniame kūno trečdalyje, lygiais kraštais, labiau apimantis mažąą kreivę bei užpakalinę sienelę. Opos dugną dengė fibrinas, skrandis ties išopejjimu buvo šiek tiek deformuotas. Gydymo metu pacientui kartotos eritrocitų masès transfuzijos, laboratoriniai tyrimai dinamikoje. Paskutinę gydymo stacionare dieną kraujo tyrimuose buvo stebima išliekanti anemija (RBC 2,82×10 12 /; HGB 88 g/l), kiti rodikliai - normos ribose. Esant stabiliai gerejjančiai paciento būklei, jis išleistas tęsti ambulatorini gydymą, skirtos didelès protonu siurblio inhibitorių (PSI) dozès (tab. Esomeprazoli $40 \mathrm{mg} \mathrm{x}$ $2 \mathrm{k} . / \mathrm{d}$.), rekomenduota planinè gydytojo gastroenterologo konsultacija dèl kartotinès FEDGS ir biopsijų paèmimo.

Praejjus 2 ménesiams po gydymosi stacionare, pacientas atvyko kontrolinei FEGDS. Stebèta teigiama dinamika gerai gyjanti opa. Endoskopinio tyrimo metu buvo matoma $0,5 \mathrm{~cm}$ dydžio fibrinu dengta opa. Paimtos biopsijos iš opos kraštų. Rastas aktyvus (++) lètinis gastritas su aktyvia limfoidine hiperplazija, H. pylori nustatyta nebuvo - itarta, jog tai klaidingai neigiamas rezultatas, todèl pacientui atliktas serologinis kraujo tyrimas iš venos, patvirtinęs $H$. pylori infekciją. Paskirtas $H$. pylori eradikacinis gydymas 10 dienų pagal schemą: tab. Esomeprasoli $40 \mathrm{mg}$ x 2 k./d., tab. Amoksicilini $100 \mathrm{mg}$ x 2 k./d., tab. Clarithromycini 500 $\mathrm{mg} \times 2 \mathrm{k}$./d. Vèliau gydymas tab. Esomeprasoli $40 \mathrm{mg}$ x 1 k./d. pratęstas dar 4 savaites.

\section{Diskusija}

Peptinès opos yra $\mathrm{HCl}$ ir pepsino sukelti skrandžio ar dvylikapirštės žarnos gleivinès pažeidimai, kurie tęsiasi iki pogleivio (submucosa) arba raumeninio sluoksnio ( laris propria) [5-7]. Skrandžio ar dvylikapirštės žarnos peptinių opų atsiradimas susijęs su dviem pagrindiniais rizikos veiksniais: Helicobacter pylori infekcija ir NVNU vartojimu $[5,6]$. Aspirino ir kitų NVNU vartojimas susijęs su 4 kartus didesne PO rizika [5]. NVNU didina PO komplikacijų, pvz., kraujavimo iš virškinamojo trakto, perforacijos ar prievarčio obstrukcijos, dažni [5]. Y. Lau ir kitų autorių sisteminèje apžvalgoje nustatyti veiksniai, didinantys PO komplikacijų riziką: senyvas amžius, vyriškoji lytis, nesaikingas alkoholio vartojimas, rūkymas, NVNU bei didelių ir mažų dozių aspirino vartojimas, $H$. pylori infekcija. Vertintuose tyrimuose aspirino (net ir mažų dozių) ir kitų NVNU vartojimas buvo dažniausias rizikos veiksnys, susijęs su kraujavimu iš skrandžio bei dvylikapirštės žarnos opų atsiradimu [2]. Pristatomu klinikiniu atveju paciento $\mathrm{PO}$ rizikos veiksniai buvo $>$ nei 60 metų, vyriškoji lytis, aktyvus rūkymas, NVNU vartojimas ir H. pylori infekcija.

Daugiau nei $30 \mathrm{mln}$. žmonių visame pasaulyje kasdien 
vartoja jiems išrašytus NVNU dèl jų analgetinio, priešuždeginimio bei antipiretinio poveikio. Nemažai vartotojų pasireiškia su virškinamuoju traktu (VT) susijęs nepageidaujamas poveikis $[7,8]$. NVNU ar aspirinas gali pažeisti bet kurią VT dali nuo stemplès iki tiesiosios žarnos. Su šių vaistų vartojimu susijusios komplikacijos 6 kartus dažnesnès viršutineje VT dalyje, nei apatinejje. Skrandžio bei dvylikapirštès žarnos PO yra dažniausia komplikacija, kuri išsivysto dèl NVNU vietinio bei sisteminio poveikio, kai gynybiniai mechanizmai tampa nepakankami [8]. Vienu pagrindinių mechanizmų, slopinančių gleivinès apsauginius mechanizmus, yra sisteminis ciklooksigenazès-1, atsakingos už prostaglandinų sintezę, slopinimas [6,7]. Prostaglandinai didina bikarbonatų bei gleivių sekreciją, gleivinès aprūpinimą krauju bei slopina ląstelių proliferaciją, kad būtų išsaugotas gleivinès barjeras. Manoma, jog kraujotakos sumažèjimas yra pagrindinè NVNU sukeliamų šalutinių reiškinių priežastis [7].

Pacientai, sergantys skrandžio opalige, skundžiasi skrandžio skausmais po valgio ir įvairiais dispepsijos simptomais, vẻliau galimas kūno masès mažejimas [7]. Mūsų aprašomu atveju pacientas išsake tipiškus skundus, būdingus skrandžio opaligei - pykinimą, silpnumą, apetito stoką bei kūno svorio kritimą. Svarbu pažymèti, jog vyresnio amžiaus asmenų simptomai gali būti nežymūs, ypač vartojant NVNU, dẻl šių vaistų analgetinio poveikio [7]. C. Lu ir kiti autoriai aprašè 6457 pacientu tyrimą, kuriems buvo atliekama profilaktinè FEGDS. Opaligè buvo nustatyta 10,7 proc. pacientų, iš kurių trečdalis neturejo jokių klinikinių simptomų [9]. Kraujavimas, pasireiškiantis kaip melena ar hematemesis, gali pasireikšti nesant įspejjamųjų simptomų beveik pusei pacientų [6]. Pristatomu klinikiniu atveju pacientas kreipèsi i gydytojus tik atsiradus ūmiam vėmimui su kraujo krešuliais.

Opaligès komplikacijos išlieka rimta sveikatos priežiūros sistemos problema [2]. Tai gali lemti tiek padideję̨s NVNU vartojimas, tiek didejantis pagyvenusių žmonių skaičius daugelyje šaliu [2]. Pagrindinès PO komplikacijos yra išliekantys simptomai, kraujavimas, perforacija ar penetracija, prievarčio obstrukcija ir supiktybejimas $[6,7,10]$. Kraujavimas iš opos yra dažniausia opaligès komplikacija, pasireiškianti 15-20 proc. pacientų, siejama su didelèmis sveikatos priežiūros išlaidomis $[7,10]$. Tyrimų duomenimis, kraujavimo iš opų paplitimas siekia nuo 19,4 iki 57,0 atvejų 100000 gyventojų, perforacija - nuo 3,8 iki 14 atvejų 100000 gyventojų. Šių komplikacijų dažnis dideja, didejjant amžiui [2].

Viršutinès virškinamojo trakto dalies endoskopinis tyrimas yra geriausias pradinis tyrimas, ittarus kraujuojančią PO, nes juo galima ne tik diagnozuoti, bet ir iš karto pradèti gydymą injekcijomis (pvz., epinefrinu), terminiais (pvz., elektrokoaguliacija bipoliaru), mechaniniais (pvz., klipsais) ar kombinuotais metodais [3,10]. Intraveniniai PSI turi būti skiriami kuo greičiau visiems pacientams, kuriems įtariamas kraujavimas iš viršutinès VT dalies [7]. Rekomendacijose nurodoma, jog pacientams, kuriems nustatomos opos ir didelès rizikos endoskopiniai radiniai, rekomenduojama skirti intraveninius PSI boliusus $(80 \mathrm{mg})$ ir po to tęsti gydymą AS̆P $8 \mathrm{mg} / \mathrm{val}$. dar 72 val.) [3]. Aprašytuoju klinikiniu atveju endoskopinio tyrimo metu aktyvaus kraujavimo nebuvo, todèl taikytas tik medikamentinis gydymas pagal rekomendacijas.

NVNU vartojimas didina pakartotinio kraujavimo iš PO riziką. 2012 metais Amerikos gastroenterologijos kolegijos paskelbtose rekomendacijose teigiama, kad jei imanoma, reikia nutraukti nuolatinį NVNU vartojimą pacientams, sergantiems opalige [10]. Jeigu nèra galimybès nutraukti gydymo NVNU, rekomenduojama skirti selektyvius ciklooksigenazès-2 inhibitorius ar naprokseno kartu su gastroprotekciniais vaistais, pavyzdžiui, PSI, histamino-2 receptoriu antagonistais ar misoprostoliu [11]. Pristatomu atveju pacientui rekomenduota nutraukti NVNU vartojimą. Tęstiniam ambulatoriniam gydymui paskirtos didelès dozès peroralinių PSI.

\section{Išvados}

1. Nesteroidiniai vaistai nuo uždegimo yra plačiai vartojamų vaistų grupè, dažnai sukelianti skrandžio ir dvylikapirštės žarnos pažeidimus bei gyvybei grèsmingas komplikacijas.

2. Nesteroidiniai vaistai nuo uždegimo gali būti skiriami tik esant indikacijų ir ịvertinus paciento opinių pakitimų bei jų komplikacijų rizikos veiksnius.

3. Esant rizikos veiksnių, tikslinga skirti PSI kaip efektyviausius gastroprotektorius.

4. Šiuo straipsniu siekiama priminti ịvairių specialybių gydytojams apie nesteroidinių vaistų nuo uždegimo žalą virškinamajam traktui ir galimas komplikacijas bei pristatyti klinikini atveji, kai trumpalaikis vaistų vartojimas buvo susijęs su dideliu skrandžio pažeidimu.

\section{Literatūra}

1. Lietuvos gyventojų sveikata ir sveikatos priežiūros ịstaigų veikla $2019 \mathrm{~m}$. Higienos instituto sveikatos informacijos centras: Vilnius, 2020. http://www.hi.lt/uploads/pdf/leidiniai/Statistikos/ LT_gyv_sveikata/leid2019.pdf

2. Lau JY, Sung J, Hill C, Henderson C, Howden CW, Metz DC. Systematic review of the epidemiology of complicated peptic ulcer disease: incidence, recurrence, risk factors and mortality. Digestion 2011;84(2):102-13.

https://doi.org/10.1159/000323958

3. Laine L. Upper gastrointestinal bleeding due to a peptic ulcer. The New England Journal of Medicine 2016;374(24):2367-2376. https://doi.org/10.1056/NEJMcp1514257

4. Dib RA, Chinzon D, de Souza Fontes LH, de Sá Teixeira AC, 
Navarro-Rodriguez T. Ulcer and bleeding complications and their relationship with dyspeptic symptoms in NSAIDs users: a transversal multicenter study. Scandinavian Journal of Gastroenterology 2014;49(7):785-789.

https://doi.org/10.3109/00365521.2014.919016

5. Vakil NB. Peptic ulcer disease: epidemiology, etiology, and pathogenesis. UpToDate 2020. https://www.uptodate.com/ contents/peptic-ulcer-disease-epidemiology-etiology-andpathogenesis?search=gastric $\% 20$ ulcer\&source=search_result $\&$ selectedTitle $=4 \sim 150 \&$ usage_type $=$ default\&display_rank $=4$

6. Lanas A, Chan FKL. Peptic ulcer disease. Lancet 2017;390(10094):613-24. https://doi.org/10.1016/S0140-6736(16)32404-7

7. Narayanan M, Reddy KM, Marsicano E. Peptic ulcer disease and helicobacter pylori infection. Missouri Medicine 2018;115(3):219-224.

8. Melcarne L, García-Iglesias P, Calvet X. Management of NSAIDassociated peptic ulcer disease. Expert Rev Gastroenterol Hepatol 2016;10(6):723-33. https://doi.org/10.1586/17474124.2016.1142872

9. Lu CL, Chang SS, Wang SS, Chang FY, Lee SD. Silent peptic ulcer disease: frequency, factors leading to "silence" and implications regarding the pathogenesis of visceral symptoms. Gastrointest Endosc 2004;60(1):34-8. https://doi.org/10.1016/S0016-5107(04)01311-2

10. Kavitt RT, Lipowska AM, Anyane-Yeboa A, Gralnek IM. Diagnosis and treatment of peptic ulcer disease. Am J Med 2019;132(4):447-56. https://doi.org/10.1016/j.amjmed.2018.12.009

11. Wilkins T, Wheeler B, Carpenter M. Upper gastrointestinal bleeding in adults: evaluation and management. Am Fam Physician 2020;101(5):294-300.

\section{NSAIDS INDUCED EXTENSIVE GASTRIC ULCERATION WITH BLEEDING. CLINICAL CASE \\ P. Tekoriutė, M. Matuliauskaitè, A. Šakalytė, L.V. Jonaitis}

Keywords: stomach cancer, ulcer, nonsteroidal anti-inflammatory drugs.

Summary

Nonsteroidal anti-inflammatory drugs (NSAIDs) are a broad class of drugs whose analgesic, antipyretic and anti-inflammatory effects are used to treat a variety of diseases. Despite their widespread use, NSAIDs can cause many side effects, often affecting the gastrointestinal tract. Gastric and duodenal peptic ulcers are the most common complication that develops due to the local and systemic effects of these drugs. Bleeding from an ulcer is the most common complication of ulcers, occurring in $15-20 \%$ of patients. This article presents a clinical case of a 63-year-old man treated for acute gastric ulcer caused by short-term but intensive treatment with NSAIDs. Just 12 days after starting NSAIDs, the patient developed acute vomiting with blood clots. Fibroesophagogastroduodenoscopy (FEGDS) revealed extensive ulceration involving approximately $1 / 3$ of the gastric circular lumen, including the small curve and posterior wall. The primary suspicion was stomach cancer, a biopsy was taken from the edges of the ulcer for differential diagnosis. Medication was applied and a positive clinical effect was obtained. The patient was discharged for further outpatient gastroenterologist's monitoring and treatment.

Correspondence to: laimas.jonaitis@1smuni.lt

Gauta 2020-12-02 